\title{
National Medical School Matching Program: optimizing outcomes
}

This article was published in the following Dove Press journal:

Advances in Medical Education and Practice

I July 2016

Number of times this article has been viewed

\section{Adam EM Eltorai \\ Alan H Daniels \\ Warren Alpert Medical School, Brown University, Providence, RI, USA}

\begin{abstract}
The medical school admissions process is inefficient and costly to both applicants and medical schools. For the many rejected applicants, this process represents a costly, unproductive use of time. For medical schools, numerous applications are reviewed that ultimately do not yield matriculants, representing a substantial inefficiency. In order to streamline the process and reduce costs, we propose the development of a national medical school matching program.

Keywords: medical school, admissions, match program
\end{abstract}

\section{Introduction}

The medical school admissions process is inefficient and costly to both applicants and medical schools. In 2014, US medical schools collectively received 731,595 applications from 49,480 applicants, yielding only 20,343 matriculants. ${ }^{1}$ For the 29,137 rejected applicants this process represented a costly, unproductive use of time. In total, 711,252 applications ${ }^{1}$ were reviewed by schools that ultimately did not yield matriculants for these schools, representing substantial inefficiency. In order to streamline the process and reduce costs, we propose the development of a National Medical School Matching Program (NMSMP).

\section{Costs to applicants}

In 2014, after completing the prerequisite coursework, Medical College Admission Test and expected extracurricular activities, 49,480 applicants submitted an in-depth primary application to medical schools, 731,595 school-specific secondary applications, prepared for interviews, and traveled to interviews around the country. ${ }^{1}$ Each applicant submitted an average of 15 applications. ${ }^{1}$ The cost to apply to 15 schools is substantial:

- Primary application fee: the majority of schools use the Association of American Medical College's American Medical College Application Service to process applications; the fee was US\$160 for the first school and \$36 for each additional school, ${ }^{2}$ representing $\$ 664$.

- Secondary application fee: required by most schools, fees typically range from $\$ 25$ to $\$ 100,{ }^{2}$ representing an estimated $\$ 937.50$.

- College service fees for transmitting transcripts from a college registrar (estimated $\$ 25)$.
Correspondence: Adam EM Eltorai

Warren Alpert Medical School of Brown University, 222 Richmond Street, Box

G-9999, Providence, RI 02903, USA

$\mathrm{Tel}+14013301420$

Email adam_eltorai@brown.edu 
- Medical College Admission Test: exam registration costs $\$ 300^{2}$ plus costs related to test preparation (eg, preparation course utilized by an estimated $50 \%$ of applicants) $\$ 2,299,{ }^{3}$ representing $\$ 2,599$.

- Flights (estimated \$400) and overnight accommodation (estimated \$90) for an approximated seven medical school interviews $(\$ 3,430)$.

- Total: $\$ 7,655.50$.

For the 29,137 rejected applicants this represented a collective wasted $\$ 223,058,303.50$. Given the average college senior graduates with $\$ 29,400$ of student loan debt, ${ }^{4}$ an additional $\$ 7,655.50$ to apply for medical school is substantial.

While waiting for admission decisions after the interview, applicants send multiple letters to the admission offices, updating them on their recent accomplishments, continued interest, intent to matriculate if accepted, along with other forms of integrity-compromising admission pleas.

Students are then accepted, rejected, or waitlisted by schools. On a designated day in May, applicants with multiple acceptances announce their choice of school and withdraw their applications elsewhere. At this point, the shuffling of waitlists begins. One spot opens up at School A and a waitlisted applicant gets accepted. That applicant makes a commitment to attend School A and withdraws her application from School B, which opens up a spot for another waitlisted applicant. This cascade effect continues throughout the summer, inconveniently requiring students to move last minute to new cities as class rosters remain unfinalized until the day before classes.

\section{Costs to schools}

For all US medical schools in 2014, 711,252 applications were reviewed by schools that ultimately do not yield matriculants at that school. ${ }^{1}$ Moreover, 437,055 of those applications ultimately did not matriculate at any medical school. ${ }^{1}$ Each medical school received an average of 5,188 applications, requiring substantial administrative staff processing time. ${ }^{1}$ Each school interviews between $10 \%$ and $35 \%$ of its applicants, ${ }^{5}$ representing an estimated 164,609 total interviews in the country. Of which, 144,266 are of applicants that ultimately do not matriculate at that school.

The typical interviewer is a physician. He/she likely spends 30 minutes reading the application, 30 minutes interviewing, 30 minutes documenting the interview. For the 144,266 unyielding interviews, this represents $216,398.8$ hours or 24.7 years of physician time.

The financial cost to schools and time involvement (to physician interviewers) could be tempered by the argument that the profession ultimately benefits by casting a wide net, interviewing $10 \%-35 \%$ of the applicants, and selecting the most suitable to the mission of the school and the needs of the profession. It could be argued that when over half of the applicants do not matriculate, it is not necessarily an unproductive use of time, personnel, and resources, but rather evidence of quality assurance in the interview process.

\section{Proposed solution}

In order to streamline the process and reduce costs, we propose the development of an NMSMP. This program will be akin to the successful National Resident Matching Program, which was "founded in 1952 by medical students seeking to standardize the residency selection process and establish a uniform date of appointment to positions in graduate medical education training programs." Similar to the National Resident Matching Program's mathematical algorithm, the proposed NMSMP will pair applicants' and admission directors' rank ordered preferences to produce an optimal fit for available class positions.

The NMSMP process will involve applying to programs utilizing a common application, registering for the match, completing interviews, and certifying ranks lists. This will require medical schools to do greater upfront screening and only extend interview offers to applicants they will rank. Once the applicants' and the admission directors' rank lists are submitted, applicants wait until match day, simultaneously receive placements, and immediately know where they will be attending school. The major barrier to implementation will be acceptance by the Association of American Medical College as the administrators of American Medical College Application Service. Such a change would require an overhaul of the current application system which represents a new cost to the profitable status quo. Comparing the admissions system with those in other countries, along with an evaluation of how and why the current system evolved, could be an instructive tool for optimizing efficiency and making the change even more compelling.

\section{Potential benefits of NMSMP}

The NMSMP promises some meaningful improvements, although the proposed solution does not resolve all 
inefficiencies in the current system. However, benefits from implementing the NMSMP may include:

- Reducing futile interviews: enhanced upfront admissions screening can reduce interviews to places that applicants would match, saving costs to both applicant and school.

- Greater student input: currently applicants have little say on where they are admitted. If applicants are given a say in their preferences, a "best fit" match may be realized providing benefit to applicants.

- Removal of superfluous documents: elimination of secondary applications and post-interview letters save financial resources and time for both applicants and admission offices administrative staff.

The medical school admissions process is currently inefficient and costly to both applicants and schools. The development of an NMSMP has the potential to streamline and simplify the admission process, reduce costs, while allowing for fair and reliable pairing applicants to the "best fit" medical schools.

\section{Disclosure}

The authors report no conflicts of interest in this work.

\section{References}

1. Association of American Medical Colleges. U.S. Medical School Applications and Matriculants by School, State of Legal Residence, and Sex, 2014. Available from: https://www.aamc.org/data/facts/applicantmatriculant/. Accessed October 29, 2015.

2. Association of American Medical Colleges. The Cost of Applying to Medical School; 2015. Available from: https://students-residents.aamc.org/financialaid/article/the-cost-of-applying-to-medical-school/. Accessed May 24, 2015.

3. Kaplan Test Prep. MCAT Prep Options (2015). Available from: http:// www.kaptest.com/mcat. Accessed May 24, 2015.

4. The Institute for College Access and Success. Quick Facts about Student Debt; 2014. Available from: http://ticas.org/sites/default/files/pub_files/ Debt_Facts_and_Sources.pdf. Accessed May 24, 2015.

5. Association of American Medical Colleges. Medical School Admission Requirements. Washington DC; 2013. Available from: https://services. aamc.org/msar/home\#null. Accessed June 16, 2016.

6. National Resident Matching Program. What is the match? Available from: http://www.nrmp.org/about/. Accessed May 24, 2015.
Advances in Medical Education and Practice

\section{Publish your work in this journal}

Advances in Medical Education and Practice is an international, peerreviewed, open access journal that aims to present and publish research on Medical Education covering medical, dental, nursing and allied health care professional education. The journal covers undergraduate education, postgraduate training and continuing medical education

\section{Dovepress}

including emerging trends and innovative models linking education, research, and health care services. The manuscript management system is completely online and includes a very quick and fair peer-review system. Visit http://www.dovepress.com/testimonials.php to read real quotes from published authors. 